Research Article

\title{
The Effect of Acid Mine Drainage Corrosion on the Creep Deformation of Cemented Gangue Backfill
}

\author{
Kun Wang $\mathbb{D},{ }^{1}$ Zhaoxing $L v \mathbb{D}^{2}$ and Haibo Tang $\mathbb{D}^{1}$ \\ ${ }^{1}$ College of Mining Engineering, Taiyuan University of Technology, Taiyuan, Shanxi, China \\ ${ }^{2}$ Key Laboratory of Insitu Property Improving Mining of Ministry of Education, Taiyuan University of Technology, Taiyuan, \\ Shanxi, China \\ Correspondence should be addressed to Kun Wang; cuinnwong@126.com and Zhaoxing Lv; alv-1001@163.com
}

Received 5 April 2020; Revised 16 September 2020; Accepted 21 September 2020; Published 20 October 2020

Academic Editor: Fernando Lusqui os

Copyright ( $) 2020$ Kun Wang et al. This is an open access article distributed under the Creative Commons Attribution License, which permits unrestricted use, distribution, and reproduction in any medium, provided the original work is properly cited.

Acid mine drainage (AMD) is a hazardous by-product of coal mining, which may intensify the creep deformation of cemented gangue backfill (CGB) in solid backfill mining. In this study, the long-term stability and creep property of CGB soaked in AMD were quantitatively measured by experimental and theoretical analysis. The uniaxial compressive strength, elastic modulus, and mass of CGB soaked in AMD, with pH of 5.56 and soaking time of 30 to 360 days, were tested. The change trend of compressive strength, elasticity modulus, and mass first increased, then decreased, and finally ended at $94.37 \%, 96.68 \%$, and $98.00 \%$, respectively. The respective creep processes of CGB soaked in AMD and untreated CGB were similar, initial creep stage lasted only for a short time, and no creep deformation occurred in the steady creep stage. Moreover, the long-term strength of CGB soaked in AMD was $98.6 \%$ of the untreated CGB. The creep law of the CGB soaked in AMD was accurately fitted by using the Kelvin model. The theoretical analysis revealed that the final creep deformation of the CGB column soaked in AMD was only $4.4 \mathrm{~mm}$. The results of this paper show the possibility of using CGB in AMD-accumulating goaf.

\section{Introduction}

China is the world's largest producer and consumer of coal due to its coal-rich and oil-poor energy reserves $[1,2]$. Till date, several measures have been introduced to expand China's share of renewable and carbon-efficient fossil-fuel energies so as to reduce coal production and consumption [3], yet coal will remain a crucial source of energy in China for at least several decades [4-6]. The underground mining method is the most common method to mine coal in China [7], and many mined-out goaf, coal gangue, and acid mine drainage (AMD) are created during the underground coal excavation [8-11]. The mined-out goaf under railways, roads, buildings, and surface water is very prone to surface subsidence and water inrush accidents [12]. Coal gangue is often discarded and accumulated in large heaps due to its inherent low heat and utilization value [13]. These gangue heaps account for a significant number of lands and cause potential hazards, such as spontaneous combustion accidents, air contamination, and soil heavy metal pollution [3]. AMD always contains metals, sulfate, and acidity [14], which is an important area of environment impact $[15,16]$. In coal mine goaf, AMD can contaminate groundwater resources and corrode buildings $[17,18]$. The use of coal gangue as the main component of backfill material of solid backfill mining (SBM) can aid in the efficient disposal of coal gangue as well as decrease the influence of surface subsidence [19-21]. Some constituents of cemented gangue backfill (CGB) may react with AMD, which leads to the decrease in the support strength and stability of backfill material in SBM [22]. Creep property is a key parameter of the backfill material of SBM, which directly affects the longterm stability of supported goaf [23]. Therefore, examination of the influences of AMD corrosion on the creep deformation of CGB is significantly important for the application and long-term stability of SBM.

The mechanical properties of CGB have increasingly attracted widespread attention [24, 25]. Yin et al. [7] 
investigated the characteristics of hydration kinetics and microstructure of fly ash cemented backfill materials based on the thermodynamic and electrical perspectives. Wu et al. [9] studied the uniaxial compressive strength of cemented gangue backfill by means of experiments. Fall and Pokharel [26] studied the strength development and microstructure of coal gangue concrete at different initial sulfate contents and temperatures. Vegas et al. [27] studied the compressive strength of the cement matrices of blended thermally activated coal gangue via experiments. Wu et al. [28] studied the influence of cement types and mixing water quality on cemented paste backfill properties. Dong et al. [29] investigated the compressive strength and flexural strength of concrete mortar under different coal gangue fine aggregate contents. Li et al. [30] used ANSYS to investigate the flexural properties of reinforced spontaneous combustion gangue concrete beams. Cihangir et al. [31] investigated the influence of the silicate modulus on the strength and stability of cemented paste backfill. Guan et al. [32] studied the effects of low temperature on the mechanical properties of coal gangue concrete through freeze-thaw cycle experiments. The long-term acid corrosion resistance of CGB soaked in AMD is the key step toward ensuring long-term support in wateraccumulating goaf of coal mines [33-35]. However, all of the aforementioned research studies have mainly focused on the influence of components and their contents on the mechanical properties of CGB, while very few researchers have investigated the effects of AMD corrosion on the creep deformation of CGB in SBM.

In this study, the mechanical properties of CGB prepared by cement, fly ash, and coal gangue were tested. Further, multistage loadings were adopted to test the creep property of CGB, which was soaked in AMD gathered from the goaf of a coal mine in China. Next, the creep law of the CGB soaked in AMD was fitted by using the Kelvin model based on the soak experimental creep curves. Finally, the creep deformation of the CGB column under AMD corrosion was investigated by using a generalized Kelvin model for SBM.

\section{Materials and Experiment Methods}

\subsection{Materials}

2.1.1. The Raw Materials of CGB. The gangues were obtained from Silaogou Mine in Datong City, Shanxi Province, China. The physical composition, mineralogical composition, main parameters of the coal gangue, and results of the leaching test on coal gangue are shown in Tables 1-4. In order to guarantee the quality of aggregate, the carbonaceous mudstone and arenaceous shale were removed before crushing. The coarse aggregate was the crushed coal gangue of which the grain size was $4.75-20 \mathrm{~mm}$, while the fine aggregate was those of which the grain size was $0.15-4.75 \mathrm{~mm}$. The physical appearance of the coarse aggregate and the fine aggregate is shown in Figure 1. The main parameters of the fine aggregate are shown in Table 5. The cement was pc32.5 cement. The fly ash was obtained from the power plant near Silaogou Coal Mine. The water was tap
TABle 1: Physical composition of coal gangue.

\begin{tabular}{lccc}
\hline Substances & Proportion & Substances & Proportion (\%) \\
\hline $\mathrm{SiO}_{2}$ & 47 & $\mathrm{TiO}_{2}$ & 1.24 \\
$\mathrm{Al}_{2} \mathrm{O}_{3}$ & 32.66 & $\mathrm{P}_{2} \mathrm{O}_{5}$ & 0.17 \\
$\mathrm{Fe}_{2} \mathrm{O}_{3}$ & 1.01 & $\mathrm{Na}_{2} \mathrm{O}$ & 0.29 \\
$\mathrm{CaO}$ & 1.18 & $\mathrm{~K}_{2} \mathrm{O}$ & 3.09 \\
$\mathrm{MgO}$ & 0.42 & $\mathrm{MnO}_{2}$ & 0.009 \\
$\mathrm{SO}_{3}$ & 0.18 & Loss on ignition & 12.64 \\
\hline
\end{tabular}

TABle 2: Mineralogical composition of coal gangue.

\begin{tabular}{lc}
\hline Minerals & Proportion (\%) \\
\hline Siltite & 8.5 \\
Medium-grained sandstone & 42.7 \\
Fine-grained sandstone & 13.6 \\
Sandy mudstone & 19.5 \\
Coal & 2.1 \\
Carbonaceous mudstone & 4.7 \\
Arenaceous shale & 3.0 \\
\hline
\end{tabular}

TABle 3: Main parameters of coal gangue.

\begin{tabular}{lc}
\hline Parameters & Value \\
\hline Mt & $0.5 \%$ \\
Mad & $0.21 \%$ \\
Aad & $88.12 \%$ \\
Vad & $76.64 \%$ \\
Fixed carbon & $2.78 \%$ \\
Total sulfur & $0.17 \%$ \\
H & $0.80 \%$ \\
CRC & 2 \\
Dry basis perch caloric value & 1.93 Qgr.d/MJ.kg \\
Received dry basis perch caloric value & 1.74 Qnet.ar/MJ.kg \\
\hline
\end{tabular}

TABLE 4: Results of the leaching test on coal gangue.

\begin{tabular}{lccc}
\hline Substances & Concentration & Substances & Concentration \\
\hline $\mathrm{Cu}$ & 0.146 & $\mathrm{Cr}(\mathrm{VI})$ & 0.001 \\
$\mathrm{Zn}$ & 0.170 & $\mathrm{Hg}$ & 0.00002 \\
$\mathrm{Cd}$ & 0.001 & $\mathrm{As}$ & 0.01 \\
$\mathrm{~Pb}$ & 0.006 & $\mathrm{Se}$ & 0.001 \\
$\mathrm{Cr}$ & 0.004 & Inorganic fluoride & 0.06 \\
\hline
\end{tabular}

water. The admixture was mainly composed of water reducer, and it was added to reduce the dosage of water from 345 to $231 \mathrm{~kg} / \mathrm{m}^{3}$ and to improve the slump of the CGB from $140 \mathrm{~mm}$ to $260 \mathrm{~mm}$.

2.1.2. AMD. The AMD was obtained from the old mine goaf at No. $14^{-3}$ coal seam of Silaogou Mine. The main sources of the AMD were water-bearing surrounding rocks and underground human activities. The chemical properties of AMD are shown in Table 6, and its chemical composition of the AMD is shown in Table 7. The $\mathrm{pH}$ of most AMD in Shanxi Province is more than $7[36,37]$; therefore, the AMD with a $\mathrm{pH}$ of 5.56 represents a relatively bad circumstance of goaf in SBM. 


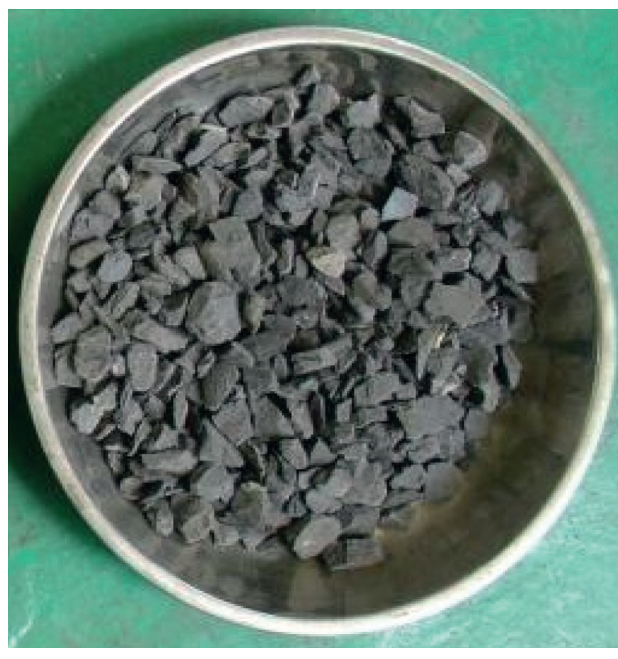

(a)

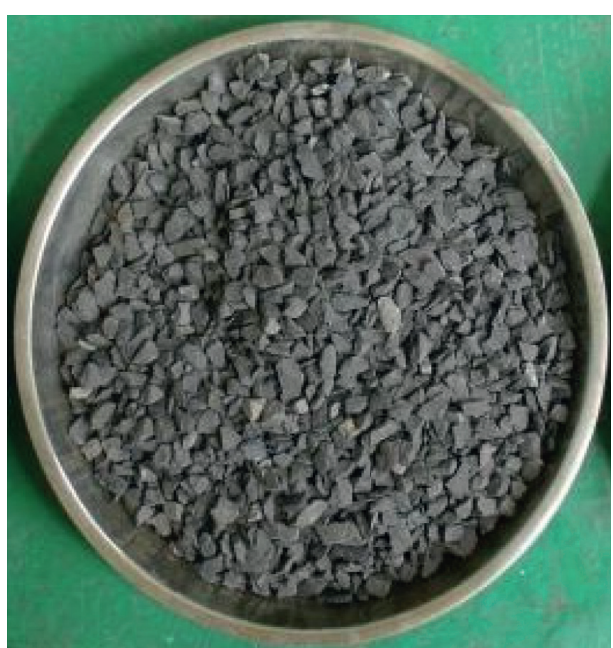

(b)

FIgURE 1: Physical appearance of crushed coal gangue: (a) coarse aggregate and (b) fine aggregate.

TABLE 5: Main parameters of the fine aggregate.

\begin{tabular}{lc}
\hline Parameters & Value \\
\hline Fineness modulus & 2.60 \\
Silt content & $3.8 \%$ \\
Clay lump content & 0 \\
Bulk density & $1370 \mathrm{~kg} / \mathrm{m}^{3}$ \\
Crush index & $14 \%$ \\
\hline
\end{tabular}

TABLE 6: Chemical property of AMD.

\begin{tabular}{lc}
\hline Chemical property & Value \\
\hline $\mathrm{pH}$ & 5.56 \\
$\mathrm{Eh}(\mathrm{mV})$ & 401.8 \\
$\mathrm{EC}(\mathrm{mS} / \mathrm{cm})$ & 1.55 \\
\hline
\end{tabular}

TABle 7: Chemical composition of AMD.

\begin{tabular}{lccc}
\hline Substances & Value $(\mathrm{mg} / \mathrm{L})$ & Substances & Value $(\mu \mathrm{g} / \mathrm{L})$ \\
\hline $\mathrm{SO}_{4}{ }^{2-}$ & 931.8 & $\mathrm{Zn}$ & 23.3 \\
$\mathrm{Na}$ & 363 & $\mathrm{Ba}$ & 12.4 \\
$\mathrm{HCO}_{3}{ }^{-}$ & 362.9 & $\mathrm{Cr}$ & 8.83 \\
$\mathrm{Mg}$ & 77.2 & $\mathrm{Ni}$ & 6.66 \\
$\mathrm{Cl}$ & 187.6 & $\mathrm{Cu}$ & 6.64 \\
$\mathrm{Ca}$ & 181 & $\mathrm{As}$ & 2.12 \\
$\mathrm{~K}$ & 47.8 & $\mathrm{Mn}$ & 0.65 \\
& & $\mathrm{~Pb}$ & 0.624 \\
$\mathrm{Fe}$ & 0.815 & $\mathrm{Hg}$ & 0.036 \\
& & $\mathrm{Cd}$ & 0.005 \\
\hline
\end{tabular}

\subsection{Specimen Preparation}

2.2.1. The CGB Specimen. The ratio of raw materials of the CGB is shown in Table 8. First, cement, fly ash, coarse aggregate, and fine aggregate were weighed using an electronic balance and then placed in a blender. Next, the mixture was whisked until the contents were evenly mixed. Tap water and admixture were added before stirring. The mixture was shaken, and the initial slump was measured. After one hour, the slump was measured again, and then the concrete was placed into a mold within $15 \mathrm{~min}$. After $24 \mathrm{~h}$, the concrete in the mold was demolded in a standard curing room, where the temperature was $18-22^{\circ} \mathrm{C}$ and the relative humidity was greater than $95 \%$. In the following 28 days, the specimens were placed in the standard curing room, apart from each other by more than $10 \mathrm{~mm}$, and the surface was kept moist [38]. The mechanical properties of CGB are listed in Table 9. According to the aforementioned procedure, the CGB specimen with the dimension of $100 \mathrm{~mm} \times 100 \mathrm{~mm} \times 100 \mathrm{~mm}$ was prepared for the CGB soaking test, and cylindrical specimens with the size of $\Phi$ $25 \mathrm{~mm} \times 50 \mathrm{~mm}$ were produced by a core-drilling machine for the creep test.

2.2.2. The Medium-Grained Sandstone Specimen. The medium-grained sandstone test specimen was taken from the roof of Silaogou Coal Mine. The medium-grained sandstone is distributed in multiple layers in the overlying strata of the No. $14^{-3}$ coal seam, with the thicknesses of $7.3,4.0,6.2$, and $5.3 \mathrm{~m}$, respectively, and a cumulative thickness of $22.8 \mathrm{~m}$, accounting for $24 \%$ of the total thickness of the overlying strata in the No. $14^{-3}$ seam. It was relatively hard and complete in this set of formations, which controlled the deformation of the overlying formations. The thickest $(7.3 \mathrm{~m})$ mediumgrained sandstone, found only $0.9 \mathrm{~m}$ away from the No. $14^{-3}$ coal seam, was the key layer in the mining process. The large rock samples of medium-grained sandstone that were collected from the Silaogou Coal Mine were sealed with paraffin and transported to the laboratory. According to the recommended method for rock mechanics testing by the International Rock Mechanics Institute, three specimens were processed with a size of $\Phi 25 \mathrm{~mm} \times 50 \mathrm{~mm}$ [39]. 
TABLE 8: Ratio of raw materials of CGB.

\begin{tabular}{lc}
\hline Raw materials & Content $\left(\mathrm{Kg} / \mathrm{m}^{3}\right)$ \\
\hline Cement & 380 \\
Fly ash & 114 \\
Coarse aggregate & 858 \\
Fine aggregate & 648 \\
Water & 231 \\
Admixture & 14 \\
\hline
\end{tabular}

TABLE 9: Mechanical properties of CGB.

\begin{tabular}{lc}
\hline Mechanical property & Value \\
\hline Compressive strength $(\mathrm{MPa})$ & 28.4 \\
Elastic modulus (MPa) & 901.17 \\
Shearing strength $(\mathrm{MPa})$ & 8.10 \\
Frictional angle $\left(^{\circ}\right)$ & 24.13 \\
\hline
\end{tabular}

\subsection{Experiment Method}

2.3.1. CGB Soaking in AMD. After 28 days of maintenance, the mass and the uniaxial compression of the $100 \mathrm{~mm} \times 100 \mathrm{~mm} \times 100 \mathrm{~mm}$ CGB specimen were recorded and then the specimen was completely soaked in AMD. The soaking container was sealed with a plastic wrap to avoid the effect of evaporation on $\mathrm{pH}$ of AMD. The experiments were divided into seven groups according to soaking time, namely, for $30,60,90,120,180,240$, and 360 days, with three samples per group. A control group, containing specimens soaked in distilled water, was also investigated for comparative analysis. When the soaking time had come to an end, the masses of CGB specimens were observed, and a uniaxial compression test was performed to measure the compressive strength and elastic modulus.

2.3.2. Creep Test. Three YDY-100 high-temperature uniaxial rock creep testers were adopted to test the creep characteristics of specimens, as shown in Figure 2(a). A pressure sensor with the maximum range of $200 \mathrm{kN}$ and measurement accuracy of $0.01 \mathrm{kN}$ was used to measure the pressure. The real-time displacement was measured using a linear variable displacement transducer sensor with the measuring accuracy of $10^{-3} \mathrm{~mm}$ and range of $10 \mathrm{~mm}$. The pressure, displacement, and temperature were automatically and directly measured in real time using a computer system, as shown in Figure 2(b). A multistage loading axial compression loading method was adopted, and the load application increment was determined according to the creep condition during the experiments. The specific steps of the uniaxial creep experiment under multistage loading are as follows.

First, the specimen was placed in the storehouse of the rock creep tester. The first stage of load was applied slowly, and the displacement was measured every minute. Second, after entering the steady-state creep stage, the interval of displacement measuring was adjusted to $20 \mathrm{~min}$. If the deformation of the specimens did not change over a period of more than at least $48 \mathrm{~h}$, it was considered that the specimens were no longer undergoing creep under the load and the next stage of load would be applied. Third, after entering the accelerated creep stage, the interval of displacement measuring was adjusted to $1 \mathrm{~min}$, until the specimen was broken.

Three creep tests were conducted. The first was a multistage loading uniaxial creep test on medium-grained sandstone specimens. The second was a multistage loading uniaxial creep test on CGB specimens in a dry state. The last was multistage loading uniaxial creep tests on CGB which was soaked in AMD, with specific steps as mentioned above, except for the fact that the storehouse was filled with AMD.

\section{Results and Discussion}

3.1. Mechanical Properties. The variation of compressive strength and elasticity modulus of CGB soaked in AMD is shown in Figure 3. The compressive strength of CGB increases at the beginning of the immersion. This result could be attributed to the following two reasons. First, CGB was soaked in water and cement hydration continued to occur, which resulted in an increase in the compressive strength and elastic modulus [40-43]. Second, the expansion stress inside CGB led to the decrease in the pore diameter or increase in the compactness because the $\mathrm{SO}_{4}{ }^{2-}$ ions in AMD reacted with the CGB to form ettringite crystals $[44,45]$. This in turn resulted in the increase in the compressive strength and elastic modulus of the CGB [40]. After soaking for 60 days, the compressive strength of CGB began to decrease, as the $\mathrm{H}^{+}$ions in $\mathrm{AMD}$ reacted with $\mathrm{CGB}$, which reduced the components such as $\mathrm{CaO}, \mathrm{Fe}_{2} \mathrm{O}_{3}$, and $\mathrm{Al}_{2} \mathrm{O}_{3}$ [46-50]. The $\mathrm{SO}_{4}{ }^{2-}$ ions could only decelerate the action of $\mathrm{H}^{+}$in the initial stage, and its effect was limited. The corrosion of $\mathrm{H}^{+}$ ions on CGB gradually became the dominant factor influencing the effect of AMD on CGB. Moreover, the volume expansion of the $\mathrm{SO}_{4}{ }^{2-}$ ion reaction products caused internal stress in CGB, which generated tiny holes and exacerbated the CGB corrosion [51]. With the gradual decrease in the compressive strength, after 120 days, it began to be lower than the original value, and after 300 days, it reached a minimum of $26.8 \mathrm{MPa}$, which was $94.37 \%$ of the original value, yet it still met the demand for CGB in SBM. After 360 days of soaking, the compressive strength was $0.3 \mathrm{MPa}$ higher than that at 300 days, which was likely caused by individual differences in the specimens.

Variation of the elasticity modulus basically followed the same trend as the compressive strength, as shown in Figure 3. Before the 90-day point, the elasticity modulus of the CGB increased, and it began to decrease further. After soaking for 360 days, the elastic modulus was the smallest, at 871.26 MPa, which was $96.68 \%$ of the original value. The corrosive effects of AMD with a $\mathrm{pH}$ of 5.56 for CGB were found to be negligible, as the CGB is a typical heterogeneous body and the performance of the same batch of concrete in laboratory tests and industrial production often fluctuates in this manner [52].

Figure 4 exhibits that the mass of CGB soaked in AMD continued to increase until 90 days and then decreased, but it was still higher than the mass before soaking. The 


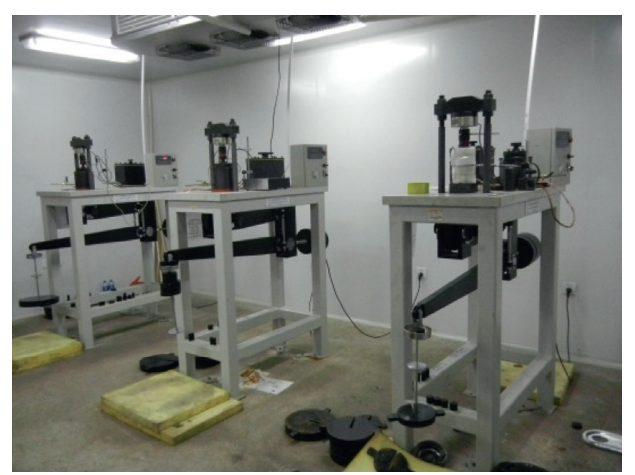

(a)

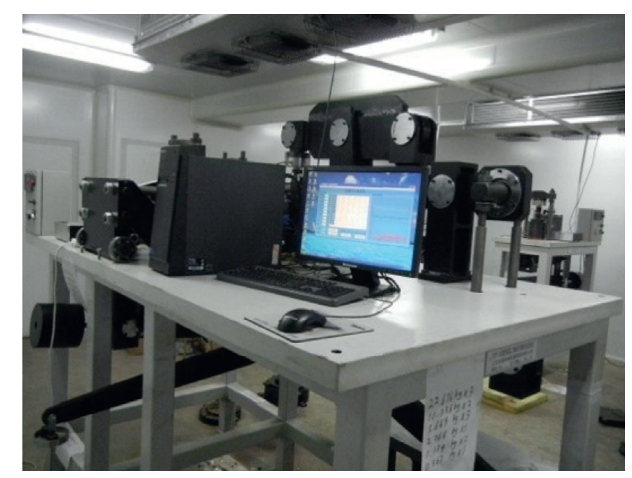

(b)

FIgURE 2: Uniaxial creep testing machine: (a) YDY-100 high-temperature uniaxial rock creep tester and (b) stress and displacement acquisition system.

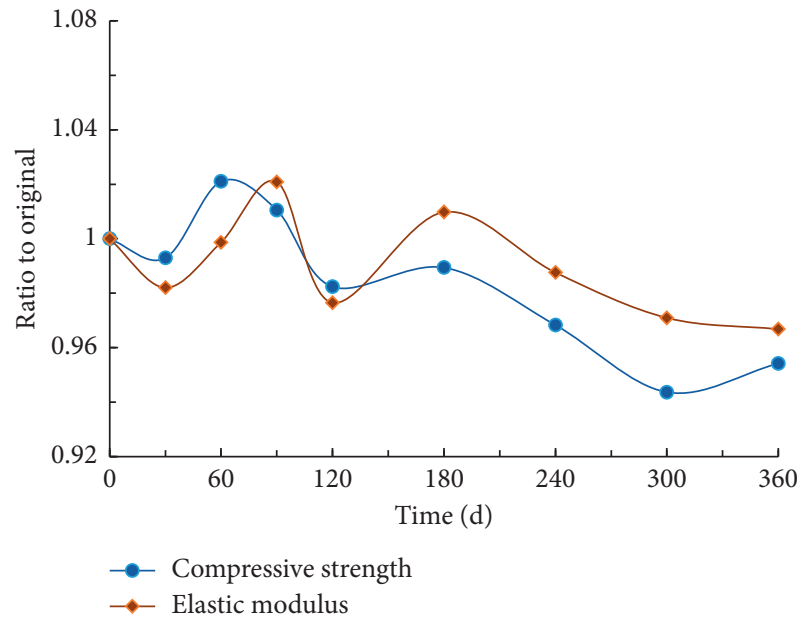

FIGURE 3: Variation of compressive strength and elasticity modulus of CGB soaked in AMD.

cause of this phenomenon was a combination of the hydration of cement and ettringite crystals produced by the $\mathrm{SO}_{4}{ }^{2-}$ ions. In order to determine the effects of acidic substances in AMD on the mass of the CGB, the influence of cement hydration was removed by eliminating the mass change of CGB soaked in distilled water [53]. The mass of CGB soaked in AMD still increased, but after 90 days, it began to decrease. It was less than the original mass at 120 days when the corrosion effect of $\mathrm{H}^{+}$ions in AMD dominated. Further, the mass of CGB continued to decrease, but the decrease rate decelerated, and at 300 days, it was basically stable. The mass of CGB soaked in AMD remained the same after 300 days and was reduced by $0.199 \%$ compared to the original mass. This revealed that AMD with a $\mathrm{pH}$ of 5.56 showed little effect on mass of CGB.

3.2. Creep Property Analysis. Various creep properties of the specimens soaked in AMD are shown in Figure 5. The loading stages of the given specimens are shown in Table 10.

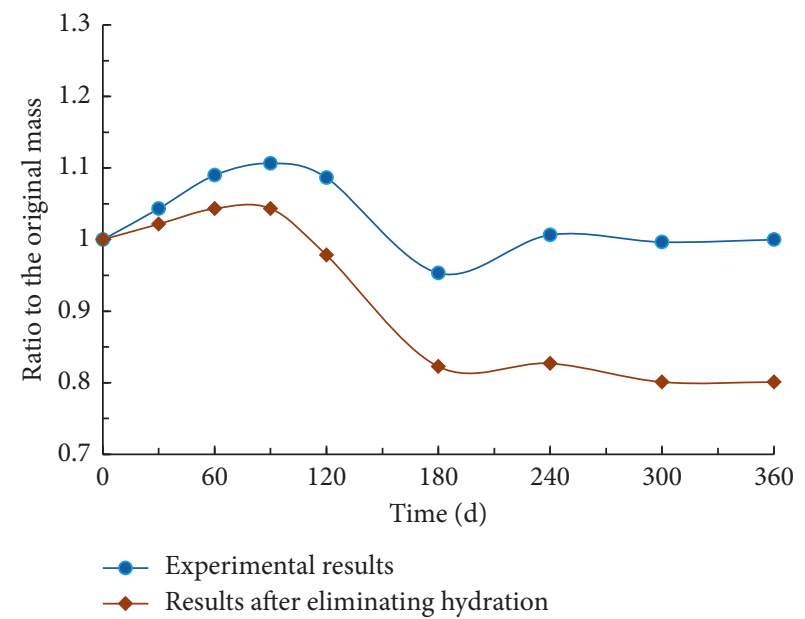

FIgURE 4: Variation of mass change of CGB soaked in AMD.

It can be observed that when the stress was lower than $10 \mathrm{MPa}$, the initial creep time lasted for a very short period, usually several hours. When the stress was higher than $20 \mathrm{MPa}$, the duration of the initial creep stage was prolonged, typically by $1-3$ days. The duration of steady-state creep was prolonged while the stress increased. The initial and steady-state creep stages of both untreated and soaked CGB were longer than those of the medium-grained sandstone. When the stress was loaded to $40 \mathrm{MPa}$, the medium-grained sandstone specimen quickly entered the accelerated creep stage and broke soon. When the stress of 28.1 MPa was applied, the untreated CGB specimen underwent a steady-state creep of 17 days and developed into the accelerated creep stage, eventually resulting in damage. When the stress of $25 \mathrm{MPa}$ was applied, the soaked CGB specimen underwent accelerated creep after a 12-day steadystate creep stage and eventually ruptured. Therefore, the long-term strength of medium-grained sandstone, untreated CGB, and CGB soaked in AMD was confirmed to be 30, 25, and $24 \mathrm{MPa}$, respectively. The values of long-term strength of the medium-grained sandstone, CGB, and CGB soaked in AMD are presented in Table 11. After soaking in AMD for 110 days, the long-term strength of CGB was $23.17 \mathrm{MPa}$, 


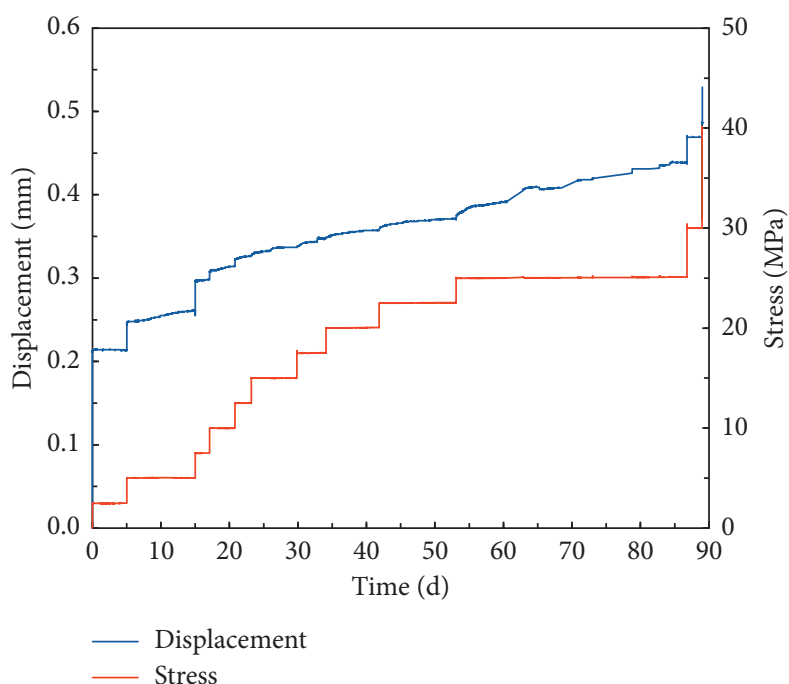

(a)

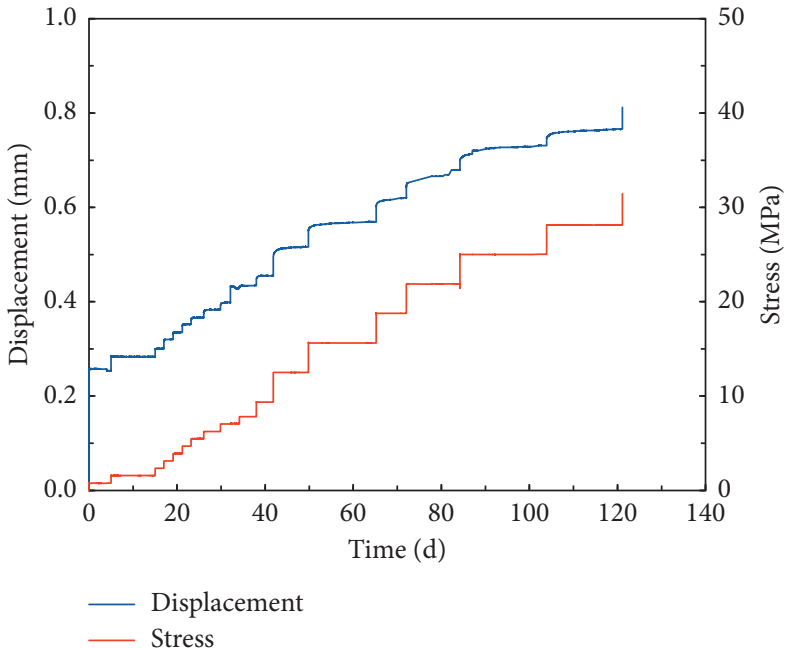

(b)

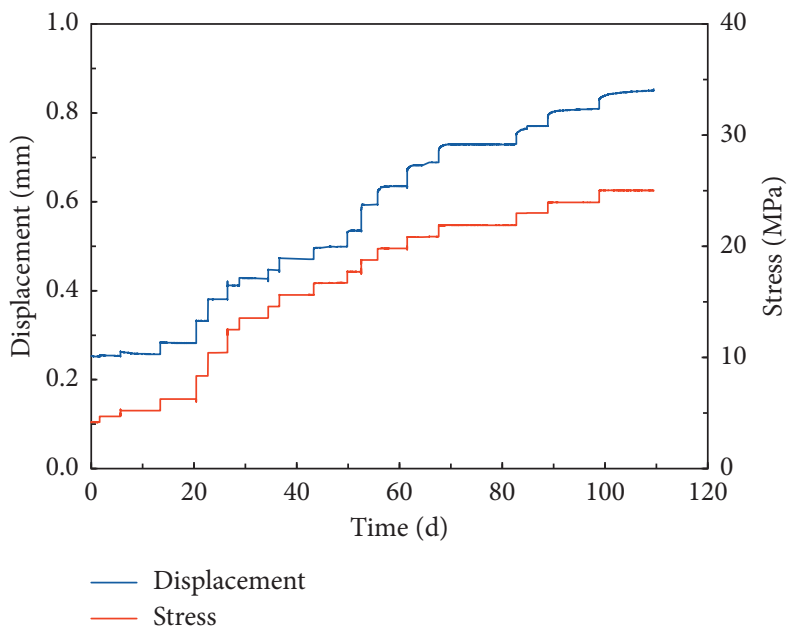

(c)

Figure 5: (a) Creep curve of the medium-grained sandstone. (b) Creep curve of the untreated CGB. (c) Creep curve of the CGB soaked in AMD.

which was $98.6 \%$ of normal CGB. It was proven that only minimal corrosion occurred on the CGB by AMD.

3.3. Fitting Analysis of Creep Curve. In order to judge the long-term stability of SBM with CGB support, the creep model was adopted to fit the results of the creep experiment. The Kelvin model was adopted through a comparison of multiple creep models, as its regularity and agreement with the experimental results were relatively good. The Kelvin model consists of a spring connected in parallel with a damper, as shown in Figure 6. The fitting parameters of the Kelvin model are listed in Table 12. follows:

The constitutive equation of the Kelvin model is as

$$
\varepsilon(t)=\frac{\sigma}{E_{k}}\left(1-e^{-\left(E_{k} / \eta\right) t}\right)
$$

where $\sigma$ represents the stress, $\mathrm{Pa} ; E_{k}$ denotes the elasticity modulus of the spring in the Kelvin body, $\mathrm{Pa} ; \eta$ represents the viscosity coefficient of paste in the Kelvin body, Pa.s; and $t$ is the time, $s$.

The generalized Kelvin model curves of medium-grained sandstone, CGB, and CGB soaked in AMD are shown in Figure 7 . The fitting curve was basically consistent with the experimental data. Figure 7(b) demonstrates that when the stress was $22.5 \mathrm{MPa}$, CGB produced a strain of only 0.002 , and creep deformation did not occur after 40 days. Figure 7 (c) illustrates that even if it was soaked in AMD, the CGB still produced only 0.0017 strain under the stress of $22.5 \mathrm{MPa}$, and after 30 days, no creep occurred. This shows that the CGB soaked in AMD could still effectively support the overburdened strata. According to the experiment results of the mechanical properties, the compressive strength and elastic modulus of CGB remained at 98.24 and $97.65 \%$, respectively, of its original value when the CGB was soaked in AMD for 110 days. 
TABLE 10: Loading stages of given specimens.

\begin{tabular}{|c|c|c|c|c|c|c|}
\hline \multirow{2}{*}{ Serial number } & \multicolumn{2}{|c|}{ Medium-grained sandstone } & \multicolumn{2}{|c|}{ Untreated CGB } & \multicolumn{2}{|c|}{ CGB soaked in AMD } \\
\hline & Stress (MPa) & Lasting time $(\mathrm{d})$ & Stress (MPa) & Lasting time $(\mathrm{d})$ & Stress $(\mathrm{MPa})$ & Lasting time $(\mathrm{d})$ \\
\hline 1 & 2.47 & 5.02 & 0.76 & 5.04 & 4.16 & 5.69 \\
\hline 2 & 5.01 & 10.00 & 1.56 & 9.99 & 5.21 & 7.74 \\
\hline 3 & 7.50 & 2.08 & 2.35 & 1.98 & 6.25 & 7.01 \\
\hline 4 & 9.99 & 3.71 & 3.12 & 2.07 & 8.34 & 2.29 \\
\hline 5 & 12.51 & 2.38 & 3.91 & 2.10 & 10.42 & 3.79 \\
\hline 6 & 15.00 & 6.65 & 4.69 & 2.02 & 12.50 & 2.31 \\
\hline 7 & 17.49 & 4.28 & 5.48 & 2.87 & 13.54 & 5.59 \\
\hline 8 & 20.01 & 7.72 & 6.24 & 3.78 & 14.58 & 2.19 \\
\hline 9 & 22.5 & 11.26 & 7.03 & 4.28 & 15.62 & 6.70 \\
\hline 10 & 24.99 & 33.71 & 7.81 & 3.89 & 16.68 & 6.51 \\
\hline 11 & 29.98 & 2.20 & 9.37 & 3.84 & 17.71 & 2.76 \\
\hline 12 & 40.00 & 0.04 & 12.49 & 7.97 & 18.76 & 3.16 \\
\hline 13 & & & 15.63 & 15.39 & 19.79 & 5.76 \\
\hline 14 & & & 18.75 & 6.83 & 20.83 & 6.12 \\
\hline 15 & & & 21.87 & 12.20 & 21.90 & 15.12 \\
\hline 16 & & & 25.00 & 19.68 & 22.96 & 2.07 \\
\hline 17 & & & 28.13 & 17.16 & 23.00 & 4.07 \\
\hline 18 & & & & & 23.95 & 10.02 \\
\hline 19 & & & & & 25.01 & 10.60 \\
\hline
\end{tabular}

TABLE 11: Long-term strength of medium-grained sandstone, CGB, and CGB soaked in AMD.

\begin{tabular}{lcccc}
\hline $\begin{array}{l}\text { Long-term strength } \\
(\mathrm{MPa})\end{array}$ & $\begin{array}{c}\text { Sample } \\
1\end{array}$ & $\begin{array}{c}\text { Sample } \\
2\end{array}$ & $\begin{array}{c}\text { Sample } \\
3\end{array}$ & $\begin{array}{c}\text { Average } \\
\text { value }\end{array}$ \\
\hline $\begin{array}{l}\text { Medium-grained } \\
\text { sandstone }\end{array}$ & 30 & 37.5 & 35 & 34.17 \\
CGB & 25 & 22.5 & 23 & 23.5 \\
CGB soaked in & 22.5 & 24 & 23 & 23.17 \\
AMD & & & & \\
\hline
\end{tabular}

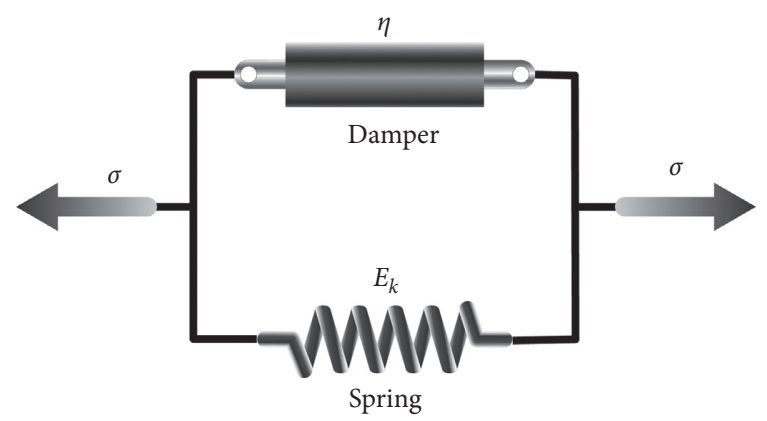

Figure 6: Illustration of the Kelvin model.

3.4. Long-Term Effects of AMD Corrosion on the Creep Deformation of the CGB Column. The deformation characteristics of the CGB columns over time are critical to the application of the CGB support column under actual stress conditions and chemical corrosion of AMD in SBM. Two key problems are involved: first, whether long-term accumulated deformation would cause a large uneven settlement on the ground, in turn destroying the column; and second, the deformation evolution of the CGB column.

The design of the support scheme is as follows: the CGB column with the side length of $5 \mathrm{~m}$ and height of
TABLE 12: Creep parameters of medium-grained sandstone, CGB, and CGB soaked in AMD.

\begin{tabular}{lccc}
\hline $\begin{array}{l}\text { Creep } \\
\text { parameters }\end{array}$ & $\begin{array}{c}\text { Medium-grained } \\
\text { sandstone }\end{array}$ & $\begin{array}{c}\text { Untreated } \\
\text { CGB }\end{array}$ & $\begin{array}{c}\text { CGB soaked } \\
\text { in AMD }\end{array}$ \\
\hline$E_{k}(\mathrm{GPa})$ & 9.5 & 12 & 15 \\
$\eta(\mathrm{GPa} \cdot \mathrm{d})$ & 95 & 80 & 60 \\
\hline
\end{tabular}

$3.4 \mathrm{~m}$ was adopted to support the roof area with the side length of $15 \mathrm{~m}$ in the No. $14^{-3}$ coal seam of Silaogou Mine. A section of the CGB column was taken for analysis, as shown in Figure 8. The model can be simplified as a cylinder with undeformed bottom surface whose top surface is subjected to load. It is assumed that the load of the model of the CGB column is a uniform load of $12 \mathrm{MPa}$ and is evenly distributed. In consideration of long-term AMD corrosion, a spring $E_{1}$ was introduced to the rheological model, in a series with the Kelvin model, as shown in Figure $9[54,55]$. Such a simplified model was adopted to perform the calculation, and the result of deformation might be greater than the actual value, signifying that it was much safer. The constitutive equation of the rheological model of the CGB column soaked in AMD is as follows:

$$
\varepsilon(t)=\frac{\sigma}{E_{k}}\left(1-e^{-\left(E_{k} / \eta\right) t}\right)+\frac{\sigma}{E_{1}},
$$

where $E_{1}$ represents elasticity modulus of the series spring, Pa.

The acid corrosion law of the elastic modulus of CGB under action of AMD in the goaf is shown in Figure 3. The power function was used to fit Figure 3, and the fitting formula for chemical corrosion is represented as follows: 


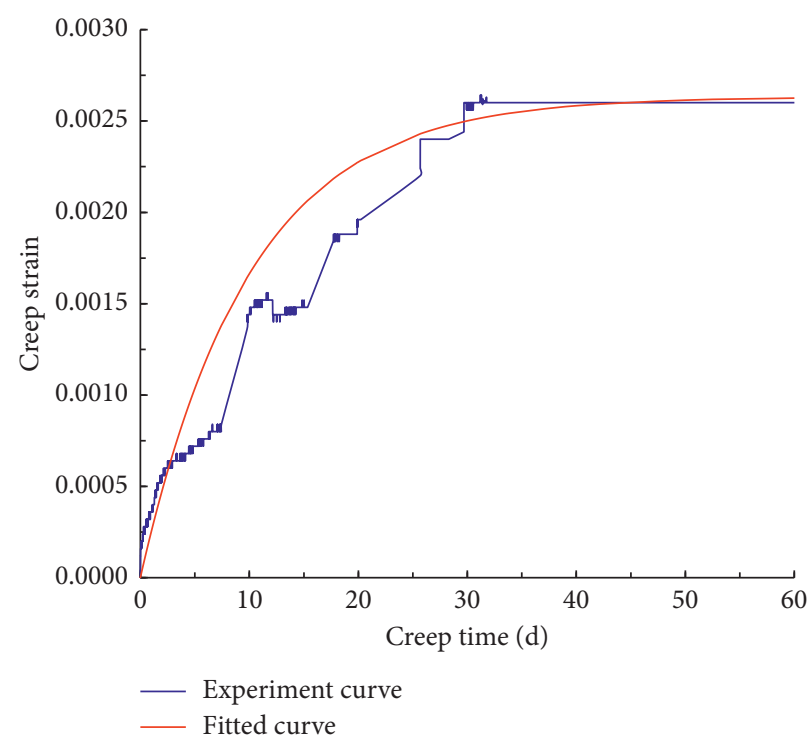

(a)

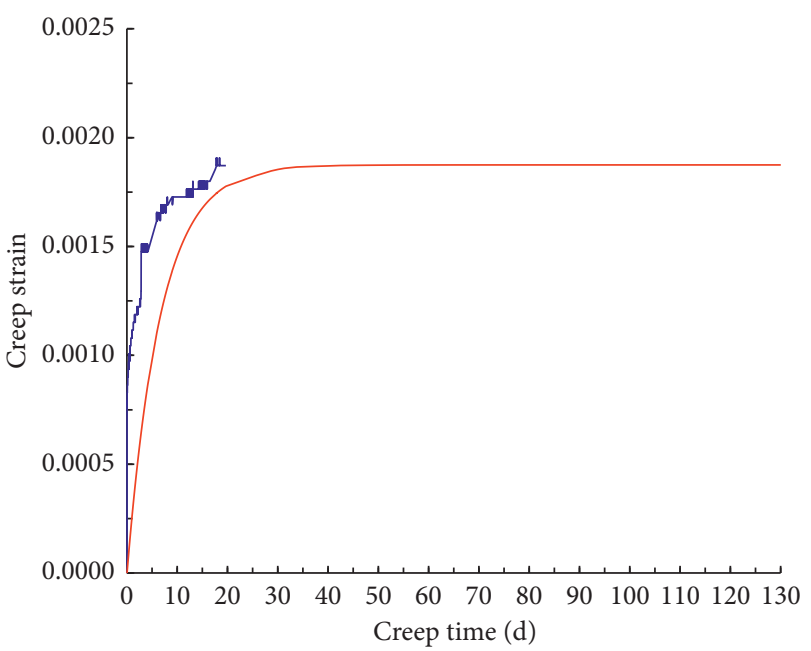

- Experiment curve

_ Fitted curve

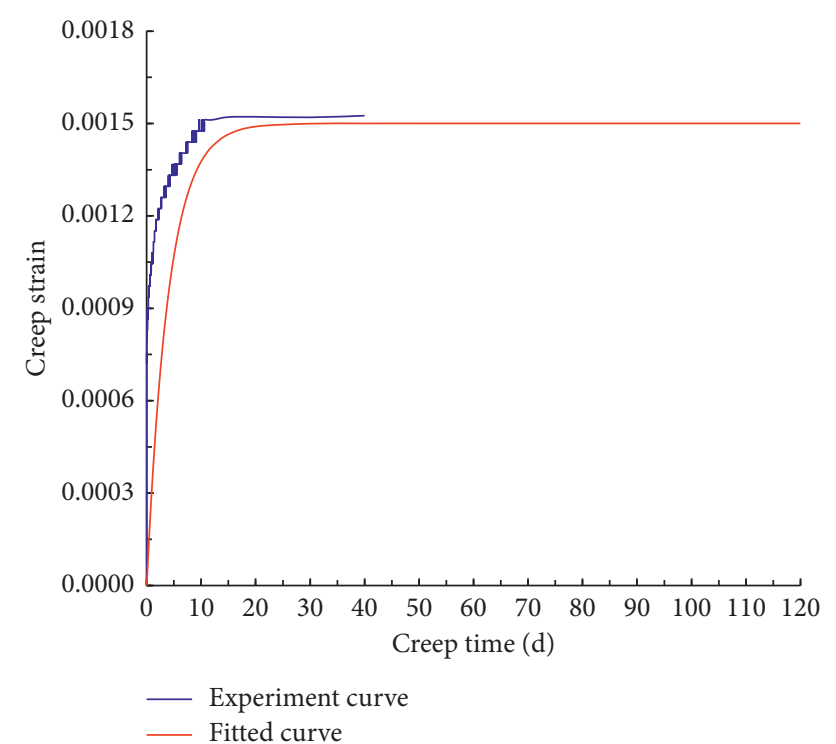

(b)

(c)

FigURE 7: (a) Fitting creep curve of medium-grained sandstone specimens. (b) Fitting creep curve of untreated CGB. (c) Fitting creep curve of CGB specimens soaked in AMD.

$$
E_{1}(t)=1.006 t^{-0.0065}
$$

The failure law of the CGB column considering the longterm AMD corrosion and creep coupling of the hydrochemical interaction in the goaf is as follows:

$\varepsilon(t)=\frac{\sigma_{0}}{E_{k}}\left(1-e^{-\left(E_{k} / \eta\right) t}\right)+\frac{\sigma_{0}}{E_{1}}=\frac{12}{15000}\left(1-e^{-0.25 t}\right)+\frac{12}{1.006 t^{-0.0065}}$.

Figure 10 shows the calculation result of equation (4). It is demonstrated that the creep deformation of the CGB column soaked in AMD mainly occurred within one month. Then the creep of the column entered the steady creep state, deformation was $2.7 \mathrm{~mm}$. Owing to the chemical action of AMD in the goaf, the CGB support column was slightly corroded, and its elastic modulus was reduced, which in turn resulted in acid corrosion deformation. The change law of deformation was that in the first month, the deformation was severe, reaching $0.75 \mathrm{~mm}$. From 30 to 360 days, the deformation then increased to $1.5 \mathrm{~mm}$. Finally, during the period of 360 to 720 days, the deformation increased from 1.5 to $1.7 \mathrm{~mm}$; thus, the deformation was $0.2 \mathrm{~mm}$ throughout the year, which was extremely weak. Certainly, the deformation would be slower after 720 days, after which it ceased. The deformation of CGB was only $4.4 \mathrm{~mm}$ after two years; then, it stabilized when two types of aging deformations were superimposed. This is the effect of AMD corrosion 

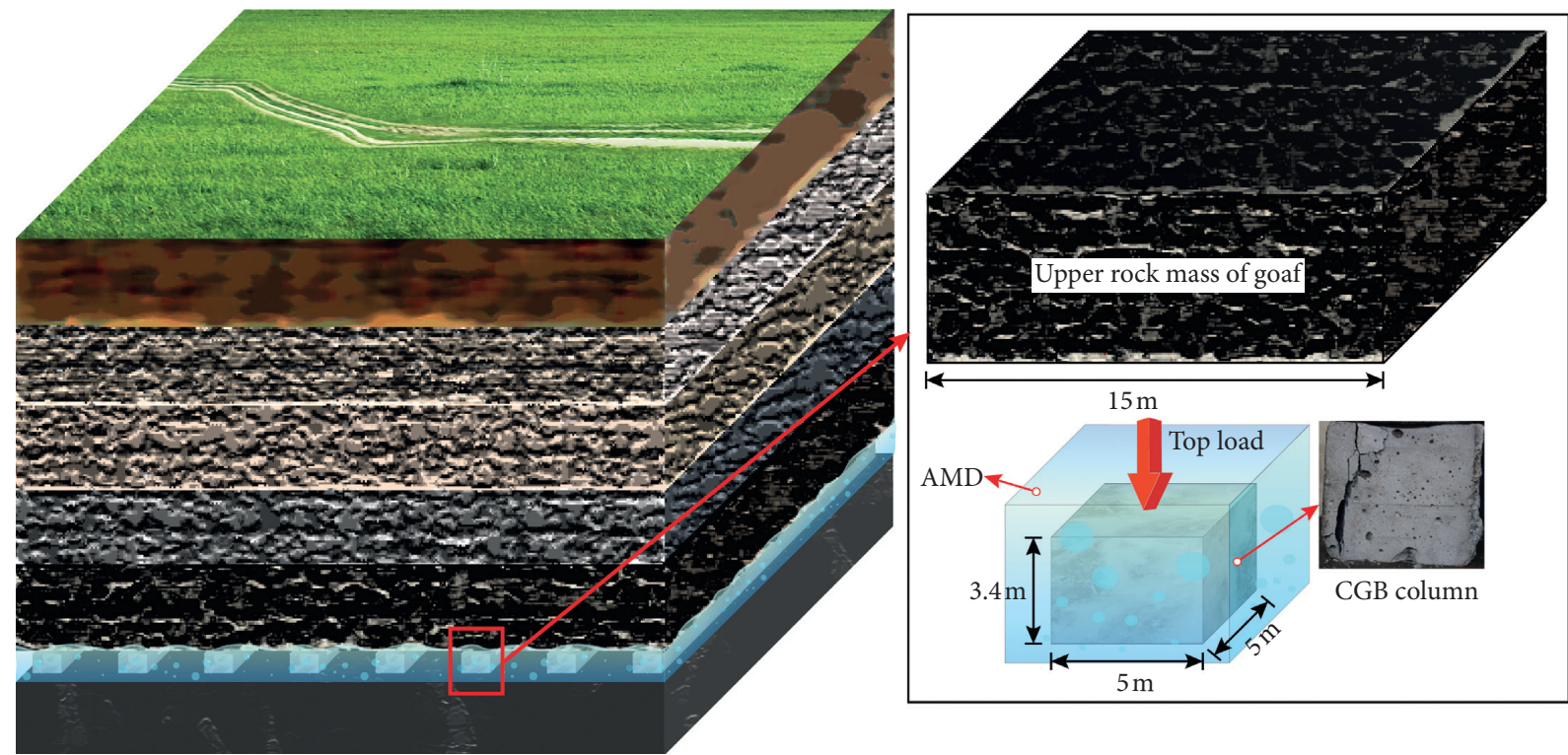

FIgURE 8: Mechanical model of the CGB column.

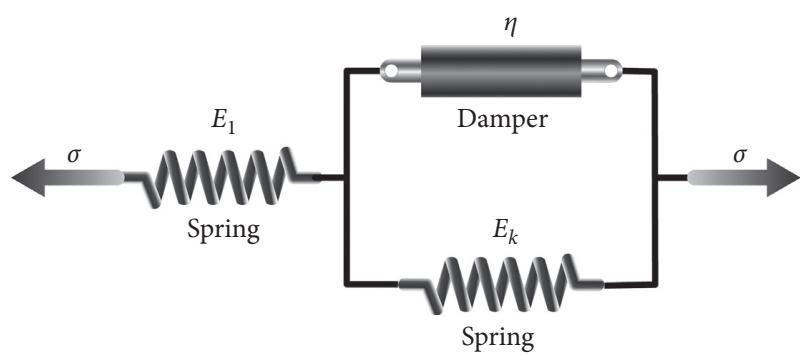

FIGURE 9: Illustration of the rheological model.

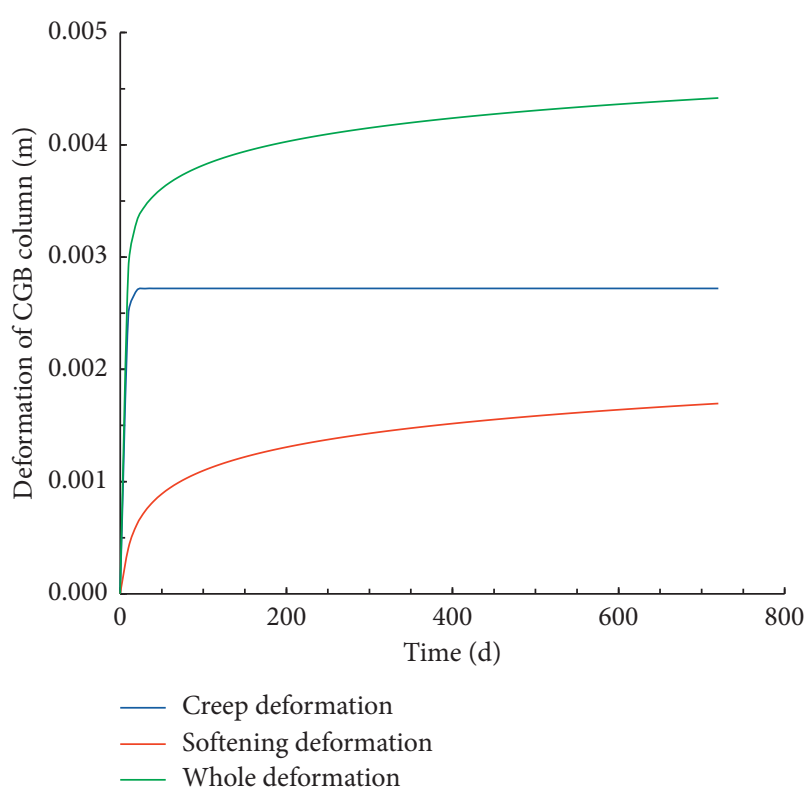

FIGURE 10: Effect of AMD corrosion on creep deformation of CGB.

on the creep deformation of the CGB in the goaf. Such a slight deformation would gradually become a uniform deformation about $30 \mathrm{~m}$ above the CGB support column and roof of the coal seam, which is negligible for ground stability.

\section{Conclusions}

The experimental CGB was soaked for 360 days in AMD with $\mathrm{pH}$ of 5.56. The combined action of cement hydration and acid corrosion caused the mechanical properties to increase first and then decrease slightly. The results indicate that under SBM conditions, the AMD corrosion on CGB was negligible.

The long-term strength of the CGB soaked in AMD was $98.6 \%$ of the untreated CGB. AMD showed little effect on the long-term strength of the CGB. The creep of CGB could be accurately fitted by the Kelvin model. According to the hydrochemical interaction rheological model of creep and effect of AMD, the creep deformation of CGB under AMD corrosion in SBM stabilized toward a negligible value in two years. The results indicate that CGB could meet the requirements of SBM under the action of AMD.

\section{Data Availability}

The data used to support the findings of this study are included within the article, and they are fully available without restriction.

\section{Conflicts of Interest}

The authors declare that they have no conflicts of interest.

\section{Acknowledgments}

The authors are grateful to Yangsheng Zhao for insight which greatly improved this manuscript and to Zijun Feng, Dong Duan, and Mengtao Cao for their help in the experiment conducted in this research. 


\section{References}

[1] Q. Wang, X. Song, and Y. Liu, "China's coal consumption in a globalizing world: insights from multi-regional input-output and structural decomposition analysis," Science of The Total Environment, vol. 711, Article ID 134790, 2020.

[2] K. Wang, H. Tang, F. Wang, Y. Miao, and D. Liu, "Research on complex air leakage method to prevent coal spontaneous combustion in longwall goaf," PLoS ONE, vol. 14, no. 3, Article ID e0213101, 2019.

[3] G. Guo, H. Li, and J. Zha, "An approach to protect cultivated land from subsidence and mitigate contamination from colliery gangue heaps," Process Safety and Environmental Protection, vol. 124, pp. 336-344, 2019.

[4] W. Liu and H. Li, "Improving energy consumption structure: a comprehensive assessment of fossil energy subsidies reform in China," Energy Policy, vol. 39, no. 7, pp. 4134-4143, 2011.

[5] R. Li and G. C. K. Leung, "Coal consumption and economic growth in China," Energy Policy, vol. 40, pp. 438-443, 2012.

[6] S. Hu, Q. Liao, G. Feng et al., "Influences of ventilation velocity on dust dispersion in coal roadways," Powder Technology, vol. 360, p. 683, 2020.

[7] B. Yin, T. Kang, J. Kang, Y. Chen, L. Wu, and M. Du, "Investigation of the hydration kinetics and microstructure formation mechanism of fresh fly ash cemented filling materials based on hydration heat and volume resistivity characteristics," Applied Clay Science, vol. 166, pp. 146-158, 2018.

[8] P. Gomes, T. Valente, D. Geraldo, and C. Ribeiro, "Photosynthetic pigments in acid mine drainage: seasonal patterns and associations with stressful abiotic characteristics," Chemosphere, vol. 239, Article ID 124774, 2020.

[9] D. Wu, Y. Zhang, and Y. Liu, "Mechanical performance and ultrasonic properties of cemented gangue backfill with admixture of fly ash," Ultrasonics, vol. 64, pp. 89-96, 2016.

[10] A. Qureshi, C. Maurice, and B. Öhlander, "Potential of coal mine waste rock for generating acid mine drainage," Journal of Geochemical Exploration, vol. 160, pp. 44-54, 2016.

[11] T. Valente, J. A. Grande, J. C. Cerón et al., "Spatial distribution of major and trace elements in a mining dam: sources and relationships among elements of environmental concern," Environmental Earth Sciences, vol. 75, no. 4, p. 342, 2016.

[12] D. Ma, H. Duan, J. Liu, X. Li, and Z. Zhou, "The role of gangue on the mitigation of mining-induced hazards and environmental pollution: an experimental investigation," Science of the Total Environment, vol. 664, pp. 436-448, 2019.

[13] Y. Wu, X. Yu, S. Hu, H. Shao, Q. Liao, and Y. Fan, "Experimental study of the effects of stacking modes on the spontaneous combustion of coal gangue," Process Safety and Environmental Protection, vol. 123, pp. 39-47, 2019.

[14] T. Valente, P. Gomes, M. A. Sequeira Braga, A. Dionísio, J. Pamplona, and J. A. Grande, "Iron and arsenic-rich nanoprecipitates associated with clay minerals in sulfide-rich waste dumps," Catena, vol. 131, pp. 1-13, 2015.

[15] T. Valente, J. A. Grande, M. L. de la Torre, M. Santisteban, and J. C. Cerón, "Mineralogy and environmental relevance of AMD-precipitates from the tharsis mines, iberian pyrite belt (SW, Spain)," Applied Geochemistry, vol. 39, pp. 11-25, 2013.

[16] T. Valente and C. Lealgomes, "Occurrence, properties and pollution potential of environmental minerals in acid mine drainage," Science of the Total Environment, vol. 407, no. 3, pp. 1135-1152, 2009.

[17] M. I. Prudêncio, T. Valente, R. Marques, M. A. Sequeira Braga, and J. Pamplona, "Geochemistry of rare earth elements in a passive treatment system built for acid mine drainage remediation," Chemosphere, vol. 138, pp. 691-700, 2015.

[18] A. M. Muliwa, T. Y. Leswifi, and M. S. Onyango, "Performance evaluation of eggshell waste material for remediation of acid mine drainage from coal dump leachate," Minerals Engineering, vol. 122, pp. 241-250, 2018.

[19] C. Zhou, G. Liu, S. Wu, and P. K. S. Lam, "The environmental characteristics of usage of coal gangue in bricking-making: a case study at Huainan, China," Chemosphere, vol. 95, pp. 274-280, 2014.

[20] X. Y. Cong, S. Lu, Y. Yao, and Z. Wang, "Fabrication and characterization of self-ignition coal gangue autoclaved aerated concrete," Materials \& Design, vol. 97, pp. 155-162, 2016.

[21] Y. Huang, J. Li, Y. Teng et al., "Numerical simulation study on macroscopic mechanical behaviors and micro-motion characteristics of gangues under triaxial compression," Powder Technology, vol. 320, pp. 668-684, 2017.

[22] M. G. Sephton and J. A. Webb, "The role of secondary minerals in remediation of acid mine drainage by Portland cement," Journal of Hazardous Materials, vol. 367, pp. 267276, 2019.

[23] Q. Sun, B. Li, S. Tian, C. Cai, and Y. Xia, "Creep properties of geopolymer cemented coal gangue-fly ash backfill under dynamic disturbance," Construction and Building Materials, vol. 191, pp. 644-654, 2018.

[24] Y. Huang, J. Zhang, Q. Zhang, and S. Nie, "Backfilling technology of substituting waste and fly ash for coal underground in China coal mining area," Environmental Engineering and Management Journal, vol. 10, no. 6, pp. 769-775, 2011.

[25] J. Zhang, Q. Zhang, Q. Sun, R. Gao, D. Germain, and S. Abro, "Surface subsidence control theory and application to backfill coal mining technology," Environmental Earth Sciences, vol. 74, no. 2, pp. 1439-1448, 2015.

[26] M. Fall and M. Pokharel, "Coupled effects of sulphate and temperature on the strength development of cemented tailings backfills: portland cement-paste backfill," Cement and Concrete Composites, vol. 32, no. 10, pp. 819-828, 2010.

[27] I. Vegas, M. Cano, I. Arribas, M. Frías, and O. Rodríguez, "Physical-mechanical behavior of binary cements blended with thermally activated coal mining waste," Construction and Building Materials, vol. 99, pp. 169-174, 2015.

[28] A. Wu, Y. Wang, H. Wang, S. Yin, and X. Miao, "Coupled effects of cement type and water quality on the properties of cemented paste backfill," International Journal of Mineral Processing, vol. 143, pp. 65-71, 2015.

[29] Z. Dong, J. Xia, C. Fan, and J. Cao, "Activity of calcined coal gangue fine aggregate and its effect on the mechanical behavior of cement mortar," Construction and Building Materials, vol. 100, pp. 63-69, 2015.

[30] G. N. Li, B. M. Wang, and M. Zhou, "Study on flexural properties of reinforced spontaneous combustion gangue concrete beams," Periodica Polytechnica-Civil Engineering, vol. 62, pp. 206-218, 2018.

[31] F. Cihangir, B. Ercikdi, A. Kesimal, S. Ocak, and Y. Akyol, "Effect of sodium-silicate activated slag at different silicate modulus on the strength and microstructural properties of full and coarse sulphidic tailings paste backfill," Construction and Building Materials, vol. 185, pp. 555-566, 2018.

[32] X. Guan, J. Qiu, H. Song, Q. Qin, and C. Zhang, "Stress-strain behaviour and acoustic emission characteristic of gangue concrete under axial compression in frost environment," Construction and Building Materials, vol. 220, pp. 476-488, 2019. 
[33] G. Madzivire, W. M. Gitari, V. R. K. Vadapalli, T. V. Ojumu, and L. F. Petrik, "Fate of sulphate removed during the treatment of circumneutral mine water and acid mine drainage with coal fly ash: modelling and experimental approach," Minerals Engineering, vol. 24, no. 13, pp. 1467-1477, 2011.

[34] D. Wu, M. Fall, and S. J. Cai, "Coupling temperature, cement hydration and rheological behaviour of fresh cemented paste backfill," Minerals Engineering, vol. 42, pp. 76-87, 2013.

[35] M. M. K. Ksiazek, "Evaluation of acid corrosion resistance of portland cement composites impregnated with polymer sulfur composite," Anti-Corrosion Methods and Materials, vol. 64, pp. 273-285, 2017.

[36] Li. Ting, "Study on groundwater pollution risk assessment of abandoned coal mine," Thesis for Doctor's Degree, China University of Mining and Technology. Xuzhou, China, in Chinese, , Thesis for Doctor's Degree, China University of Mining and Technology. Xuzhou, China, in Chinese2014.

[37] C. Bi, "Research on the treatment of coal mine drainage and resource utilization," Thesis for Master's Degree, Shanxi University. Taiyuan, China, in Chinese, , Thesis for Master's Degree, Shanxi University. Taiyuan, China, in Chinese2008.

[38] J. Bérard, R. Roux, and M. Durand, "Performance of concrete containing a variety of black shale," Canadian Journal of Civil Engineering, vol. 2, pp. 58-65, 2011.

[39] J. W. Dudley, M. Brignoli, and B. R. Crawford, "ISRM suggested method for uniaxial-strain conpressibility testing for reservoir geomechanics," Rock Mechanics and Rock Engineering, vol. 49, pp. 4153-4178, 2016.

[40] W. B. Jeffrey, M. J. Hamlin, and A. L. Richard, "Mechanisms of cement hydration," Cement and Concrete Research, vol. 41, pp. 1208-1223, 2011.

[41] L. Yang, H. Wang, A. Wu et al., "Effect of mixing time on hydration kinetics and mechanical property of cemented paste backfill," Construction and Building Materials, vol. 247, p. 118516, 2020.

[42] M. Zajac and M. Ben Haha, "Experimental investigation and modeling of hydration and performance evolution of fly ash cement," Materials and Structures, vol. 47, no. 7, pp. 1259-1269, 2014.

[43] P. Hou, S. Kawashima, D. Kong, D. J. Corr, J. Qian, and S. P. Shah, "Modification effects of colloidal nano $\mathrm{SiO}_{2}$ on cement hydration and its gel property," Composites Part B: Engineering, vol. 45, no. 1, pp. 440-448, 2013.

[44] B. Lothenbach, G. Le Saout, E. Gallucci, and K. Scrivener, "Influence of limestone on the hydration of Portland cements," Cement and Concrete Research, vol. 38, no. 6, pp. 848-860, 2008.

[45] M. Frías, "The effect of metakaolin on the reaction products and microporosity in blended cement pastes submitted to long hydration time and high curing temperature," Advances in Cement Research, vol. 18, no. 1, pp. 1-6, 2006.

[46] Y. F. Fan, Z. Q. Hu, Y. Z. Zhang, and J. L. Liu, "Deterioration of compressive property of concrete under simulated acid rain environment," Construction and Building Materials, vol. 24, no. 10, pp. 1975-1983, 2010.

[47] Z. Wang, Z. Zhu, X. Sun, and X. Wang, "Deterioration of fracture toughness of concrete under acid rain environment," Engineering Failure Analysis, vol. 77, pp. 76-84, 2017.

[48] M. Mahdikhani, O. Bamshad, and M. Fallah Shirvani, "Mechanical properties and durability of concrete specimens containing nano silica in sulfuric acid rain condition," Construction and Building Materials, vol. 167, pp. 929-935, 2018.
[49] X. Zuo and W. Sun, "Full process analysis of damage and failure of concrete subjected to external sulfate attack," Journal of the Chinese Ceramic Society, vol. 37, no. 7, pp. 1063-1067, 2009, in Chinese.

[50] K. Wang, B. Ma, and H. Zhang, "Effect of mineral admixture on deterioration of concrete under acid rain attack," Journal of Building Materials, vol. 16, no. 3, pp. 416-421, 2013, in Chinese.

[51] T. Sakamoto, N. Yoshida, H. Harada et al., "A study on the correlation between the photoinduced volume expansion and the internal stress in hydrogenated amorphous silicon," Journal of Non-Crystalline Solids, vol. 266-269, pp. 481-485, 2000.

[52] B. Persson, "Correlating laboratory and field tests of creep in high-performance concrete," Cement and Concrete Research, vol. 31, no. 3, pp. 389-395, 2001.

[53] Y. Zhang, Y. Fan, and J. Liu, "Experimental study on compressive performance of concrete C30 in simulated acid environment," Journal of Building Materials, vol. 13, no. 1, pp. 105-110, 2010, in Chinese.

[54] S. T. Nguyen, "Generalized Kelvin model for micro-cracked viscoelastic materials," Engineering Fracture Mechanics, vol. 127, pp. 226-234, 2014.

[55] D. Zhao, L. Jia, M. Wang, and F. Wang, "Displacement prediction of tunnels based on a generalised Kelvin constitutive model and its application in a subsea tunnel," Tunnelling and Underground Space Technology, vol. 54, pp. 29-36, 2016. 